\title{
Irish eyes smiling as dispensing fees are lifted
}

$\mathrm{C}$ anadians have long envied the United Kingdom's national pharmaceutical program, which covers about $95 \%$ of all drugs — all but a notorious "black list" of about 3000 drugs — and typically leaves patients on the hook only for dispensing fees.

That envy just got greener as Northern Ireland joined Wales and Scotland in announcing that it will abolish dispensing fees for prescription drugs, effective April 2010. In the interim, dispensing fees were reduced to $£ 3$ from $£ 7$ (to \$5.57 from \$13) as of Jan. 2.

"A cradle-to-grave health service, free at the point of delivery, is the founding principle of the NHS [National Health Service], which was founded 60 years ago this year. It is a principle that I, and the entire population of Northern Ireland, wholeheartedly support," Northern Ireland Health Minister Michael McGimpsey told reporters while announcing the policy change.

The move follows in the footsteps of Wales, which last year abolished all dispensing fees, while Scotland has indicated that it plans to follow suit in the next few years. England plans to remove dispensing fees only for cancer drugs.

The National Health Service, established in 1946, provides free health care to all UK residents. In 1952, legislative amendments allowed for charges to be made to prescriptions at the time of dispensing. The cost has risen from 20 pence (about 22 cents) in 1979 to just under $£ 7$ today.

Critics, such as Ulster Unionist
Party member Robert Coulter, have charged that dispensing fees prevent many from getting the prescription medication they need to manage their illnesses, particularly cancer.

Canadian Pharmacists Association Executive Director Jeff Poston says dispensing fees vary by province. No government has moved to absorb such fees on the part of all its residents, although some pick them up for select groups, he adds. For example, Quebec guarantees free prescriptions for elderly persons receiving social assistance, welfare recipients and children. Most other provinces subsidize at least a measure of prescription costs faced by their elderly. — Lesley Ananny, Ottawa, Ont.

DOI:10.1503/cmaj.081758

\section{DISPATCH FROM THE MEDICAL FRONT}

\section{Hard hearts and horse- drawn carts}

$\mathrm{T}$ he signs are what first caught my attention: "Welcome to Chesley - Population: 5000. Don't park here - Horse Drawn Carts only."

I am in Chesley, Ontario, for Discovery Week - a program organized by the medical school at The University of Western Ontario, in which first-year medical students are sent to rural communities across southwestern Ontario for week-long clinical electives. For many of us, this is our first experience in a small town, let alone learning how to practise medicine in one.

My supervisor is a family physician. As one of the only doctors in Chesley, her medical responsibilities are many - from emergency medicine to palliative care. She enjoys the variety in her work, but the flip side to having such a broad-based practice is the overwhelming volume of patients she sees each day. Rural family physicians, she points out to me, are some of the most overworked in the nation.

While seeing patients at the local emergency department, I try to get a sense of what they think is satisfying

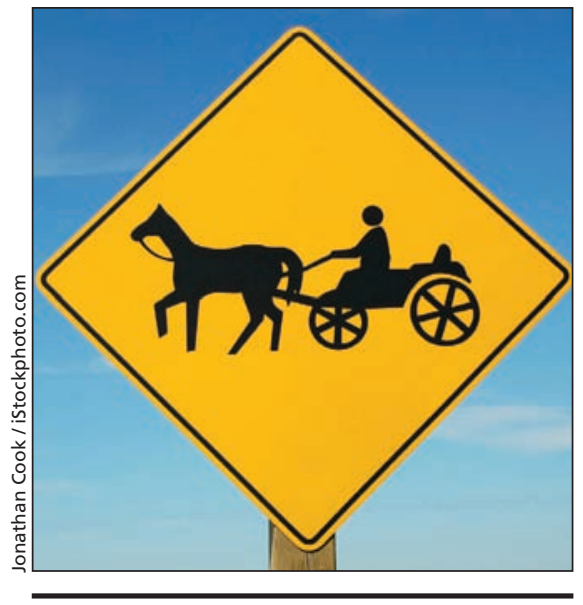

Rural Ontario signs surprise medical student.

and frustrating about the health care they receive. Almost invariably, these patients say they are most frustrated about not having access to a family physician. In communities across southwestern Ontario, small and large alike, there are long lists of patients waiting to sign up with family physicians. Chesley, it seems, is no exception to the rule.

Near midnight, a teenager enters the emergency room with blood smeared all over his T-shirt. He was sharpening a hunting knife and accidentally cut his finger on the blade. As my supervisor gets ready to suture his wound, she tells me about the special needs of rural patients. Farming-related injuries are commonplace.

A lot of patients ask me whether I will return to work here as a doctor someday.

It would take a really hard heart to say no to them.

Recently, my anatomy professor was demonstrating the pericardial membrane. "Notice the thickness of the membrane - a very hard-hearted man indeed," he jokes.

As for me, I will not be caught dead accused of hard heartedness. - George Jacob, London, Ont.

DOI:10.1503/cmaj.081941

CMAJ invites contributions to "Dispatches from the medical front," in which physicians and other health care providers offer eyewitness glimpses of medical frontiers, whether defined by location or intervention. Submissions, which must run a maximum 400 words, should be forwarded to: wayne.kondro@cmaj.ca 